\title{
Establishing Prospective Road Traffic Injury Surveillance in India: Challenges and Solutions
}

\author{
Shailaja Tetali*1, Lakshmi Josyula ${ }^{1}$, Shivam Gupta ${ }^{2}$, Shirin Wadhwaniya ${ }^{2}$, G Gururaj $^{3}$ and \\ Kent Stevens ${ }^{2}$
}

${ }^{1}$ Indian Institute of Public Health- Hyderabad, Hyderabad, India; ${ }^{2} I R U$, Baltimore, MD, USA; ${ }^{3}$ NIMHANS, Bangalore, India

\section{Objective}

To describe the challenges and lessons learned in establishing road traffic injury surveillance in two large government teaching hospitals in two States of South India, with solutions that eventually helped streamline the process.

\section{Introduction}

Low- and Middle-Income Countries (LMIC) disproportionately bear the high burden of injuries, with $90 \%$ of all deaths due to injury occurring in these countries ${ }^{1}$. In India, data on pre-hospital care of the injured is either absent or incomplete. The Bloomberg Philanthropies Global Road Safety Program is a five-year (20102015) project implemented by a consortium of partners to improve road safety in $10 \mathrm{LMICs}^{2}$. The risk factors being addressed in India are reduction of drink driving and increasing helmet use ${ }^{3}$. Up to 16 months of data from two large hospitals in Hyderabad (population 8 million) were retrospectively reviewed to examine the burden of road traffic injuries. Unfortunately, key information on the following was incomplete: alcohol use; location and activity of patient at the time of injury; nature of collision; vehicle in which patient was traveling; striking vehicle and type of road user. Information on the presence of safety equipment like helmet and seatbelt, and occurrence of prehospital care was uniformly absent. To overcome the information gap, round-the-clock injury surveillance was established in July 2013 in Hyderabad and in June 2014 in Visakhapatnam.

\section{Methods}

Hospital surveillance data were collected round-the-clock using a validated paper form. However, this abstract only describes the challenges encountered while establishing the surveillance system in the two states. Problems and concerns were identified through personal discussions of data-collection experiences through field notes, review of data-collection forms, and field observation of data-collection process by the investigators. Corrective action was undertaken when indicated.

\section{Results}

The challenges encountered and solutions employed are described below:

\section{Conclusions}

There are many challenges in establishing surveillance systems for road injuries in India, predominantly rapid staff turnover, heavy workload and the absence of already existing data recording and management in hospitals. Pending administrative solutions such as improved staffing and posting, the chief measures to address these challenges were sustained dialogue and rapport-building with hospital administrators, training of data collectors, and enlisting the aid of bridge personnel, such as interns. Reiterating the value of surveillance data to negotiate for hospital resources commensurate with the high burden of road injuries may help convince hospital administrators to sustain such surveillance initiatives.

\begin{tabular}{|l|l|}
\hline Challenge & Solution \\
\hline $\begin{array}{l}\text { Delays in obtaining permissions from government } \\
\text { hospitals }\end{array}$ & $\begin{array}{l}\text { Persistent efforts in engaging the hospital leadership, } \\
\text { including frequent meetings to obtain 'buy-in' }\end{array}$ \\
\hline $\begin{array}{l}\text { Recurrent turnover of the appointed hospital } \\
\text { superintendents because of frequent transfers }\end{array}$ & $\begin{array}{l}\text { Made contact with each new superintendent, explained } \\
\text { objectives of survelllance, and established rapport } \\
\text { afresh }\end{array}$ \\
\hline $\begin{array}{l}\text { Existing hospital staff refused to collect data, citing } \\
\text { heavy workload }\end{array}$ & Hired dedicated data collectors round-the-clock \\
\hline $\begin{array}{l}\text { Adjustment and inter personal issues between data } \\
\text { collectors and hospital staff, due to intrinsic } \\
\text { hierarchies }\end{array}$ & $\begin{array}{l}\text { Data collectors helped the hospital staff with their } \\
\text { routine work in the casualty and eventually gained their } \\
\text { confidence and cooperation }\end{array}$ \\
\hline $\begin{array}{l}\text { Data quality issues, especially completeness and } \\
\text { accuracy }\end{array}$ & $\begin{array}{l}\text { Training of data collectors included } 2 \text { day classroom } \\
\text { sessions on trauma care, case studies and the tool, 1 } \\
\text { week induction training in the hospital and frequent re- } \\
\text { training when needed }\end{array}$ \\
\hline $\begin{array}{l}\text { Quick transfer (within minutes) of patients from } \\
\text { the casualty, either to discharge or to the ward, } \\
\text { leading to incomplete data }\end{array}$ & $\begin{array}{l}\text { Hired interns from the same hospital who followed up } \\
\text { patients in the ward and completed data collection }\end{array}$ \\
\hline
\end{tabular}

Challenges and solutions

\section{Keywords}

Injury surveillance; Establishing systems; India; Challenges, solutions; Public health practice

\section{Acknowledgments}

This work was conducted as part of the Global Road Safety Program, funded by Bloomberg Philanthropies.

\section{References}

1.Stevens et al. Establishing hospital-based trauma registry systems: lessons from Kenya. Injury, Int. J. Care Injured 44 S4 (2013) S70-S74

2. Editorial: Road Safety in 10 Countries: A Global Opportunity A A. Hyder, D Bishai

3. Qualitative study to explore stakeholder perceptions related to road safety in Hyderabad, India. Tetali S, Lakshmi JK, Gupta S, Gururaj G, Wadhwaniya S, Hyder AA

\section{*Shailaja Tetali \\ E-mail: shailaja.t@iiphh.org}

